\title{
6x6: um balanço da literatura infantil portuguesa contemporânea
}

\author{
6x6: An assessment of current Portuguese children's literature
}

\author{
Ana Margarida Ramos \\ CIDTFF - Universidade de Aveiro \\ anamargarida@ua.pt \\ Recibido: febrero de 2015. Aceptado: marzo de 2015
}

\begin{abstract}
Resumo: Pretende-se, com este estudo, proceder à caracterização das tendências contemporâneas da literatura para infância e juventude em Portugal nos últimos anos, dando especial relevo à criação literária e à ilustração dos textos, área onde vários criadores se têm distinguido internacionalmente. Procederse-á, igualmente, à caracterização da edição para a infância, identificando editoras relevantes e especializadas, mas também as tendências em termos de tradução. A legitimação da literatura infantil também será analisada, com a enumeração de algumas áreas de particular relevo.
\end{abstract}

Palavras-chave: literatura para a infância; ilustração; edição; contemporaneidade; legitimação

\begin{abstract}
It's our purpose to proceed to the characterization of contemporary trends in children's literature and young adults' fiction in Portugal in recent years, with special emphasis on literary texts and illustration, area where various creators have distinguished themselves internationally. We will also characterise the publishing market for children, by identifying relevant and specialized publishers, as well as the latest trends in translation. The legitimacy of children's literature will also be analysed, with the identification of some areas of particular importance.
\end{abstract}

Keywords: Children's literature; Illustration, Publishing; Contemporaneity; Legitimation 


\section{INTRODUÇÃO: TENDÊNCIAS DA EDIÇÃO CONTEMPORÂNEA PORTUGUESA PARA A INFÂNCIA E A JUVENTUDE}

Nos últimos anos, em resultado de vários fatores, alguns claramente afastados do domínio literário, como a implementação do Plano Nacional de Leitura ou o investimento nas redes nacionais de Bibliotecas, públicas e escolares, a edição para crianças e jovens sofreu um estímulo considerável, tanto em termos de obras originais, como de traduções de publicações estrangeiras. O reforço da legitimação tem igualmente marcado a última década, oferecido pelas seleções oficiais escolares, mas também por prémios literários e de ilustração, a par da atenção por parte da academia, com o aumento de teses de mestrado e de doutoramento sobre a literatura para a infância, para além da investigação produzida no âmbito de projetos científicos. E ainda que a recente crise económica e social se faça sentir com especial relevo no mercado editorial, a verdade é que este segmento editorial tem sido aquele que melhor tem resistido às abruptas quedas nas vendas de livros.

Pretendemos, deste modo, procurar caracterizar o panorama editorial destinado à infância e juventude, com especial relevo no universo literário, dando conta das tendências recentes, quer ao nível da escrita como da ilustração, sem esquecer o universo da tradução e da própria edição, dado o aparecimento de várias editoras especializadas. Também serão enumerados os principais desafios que a literatura para os mais novos encontra, bem como as dificuldades decorrentes do seu lugar periférico/marginal no sistema literário, mantendo-a arredada de publicações de referência ou dos currículos da maioria das formações de pós-graduação em literatura, por exemplo.

Como critério de organização deste texto, e por uma questão de coerência interna do mesmo, escolhemos a simbólica unidade da meia dúzia, pelo menos no contexto cultural português, um pouco mais de uma mão cheia do que melhor se tem feito em Portugal nos anos mais recentes. Como em qualquer seleção, ficarão obviamente excluídos autores, ilustradores, editoras e obras de referência e de qualidade assinalável em todas as áreas. Esta seleção tem, sobretudo, um cariz de divulgação e não pretende — por limitações óbvias- ser exaustiva ou final, devendo ser entendida como um contributo para a caracterização do panorama literário português destinado sobretudo aos leitores mais jovens, colmatando a ausência de estudos de cariz histórico ou mesmo bibliográfico nos últimos 15 anos. Depois das obras clássicas e fundadoras de Esther de Lemos (1972), Maria Laura Bettencourt Pires (1983), Natércia Rocha $\left(1984^{1}\right)$ e, já na década de 90, de José António Gomes (1998), todas situadas no âmbito da historiografia da produção literária para a infância e juventude, tem faltado a sua atualização, pese embora os notáveis esforços de Sara Reis da Silva (2012), numa tese de Doutoramento dedicada à obra infantil de Manuel António Pina, para a sua contextualização e respetivo enquadramento. Estudos panorâmicos têm igualmente sido levados a cabo no âmbito das atividades da

1 Edições revistas e atualizadas deste volume foram publicadas posteriormente, em 1992 e 2001 . 
rede LIJMI, coordenada por Blanca-Ana Roig Rechou, e publicados nas Edicións Xerais de Galiza, nomeadamente em 2007, 2009, 2011, 2012 e 2013.

Em traços gerais, e recuperando um estudo anterior dedicado a este assunto (Ramos, 2012), diríamos que, em breves linhas, a edição para a infância e juventude em Portugal no virar do milénio e nos primeiros anos deste século é marcada pela consolidação dos autores que, desde há décadas, mas sobretudo a partir dos anos 70 e 80, publicam, com assiduidade para o público infantil; pelo surgimento de novos autores que, fruto de Prémios ou vindos de outros meios, como o jornalismo e o ensino, começaram, nos últimos anos, a publicar para a infância; pela colaboração mais ou menos pontual de autores que não escrevem habitual e assiduamente para aquela faixa etária mas que lhe têm dedicado volumes muito interessantes, como aconteceu com os portugueses José Saramago, Lídia Jorge, Mário Cláudio, ou com o moçambicano Mia Couto e os angolanos José Eduardo Agualusa e Ondjaki; pela publicação de traduções de obras relevantes - clássicas e contemporâneas- permitindo o acesso dos leitores à produção internacional de referência; pelo desenvolvimento crescente da componente ilustrativa com o aparecimento de um número considerável de ilustradores e criadores de grande qualidade, cujo reconhecimento é também feito em termos internacionais; pelo surgimento de editoras - portuguesas e estrangeiras (galegas, p. e.) especialmente vocacionadas para a publicação e divulgação da literatura para a infância e juventude.

Em termos mais específicos, a escrita para a infância mantém o interesse pela reescrita da tradição oral, tanto em termos de procura de fidelidade e de divulgação dos textos, como na criação de universos subversivos e paródicos, pelo uso criativo e inovador - às vezes subversivo e com intenções simultaneamente lúdicas e didáticas - da língua, explorando todas as suas potencialidades (gráficas e visuais, sonoras, rítmicas e melódicas, semânticas, simbólicas...), pelo recurso ao humor, obtido através da utilização dos mais diversos tipos de cómico, muitas vezes combinados entre si, pela recriação de universos próximos dos infantis - casa, família, escola - promovendo o reconhecimento e a identificação dos leitores com os ambientes e situações retratadas, pela emergência, sobretudo nos últimos anos, de universos e temáticas fraturantes, às vezes perturbadores e polémicos, como os ligados à morte, à violência ou ao sexo.

\section{PANORAMA ATUAL DA LIJ PORTUGUESA}

As seis categorias escolhidas para a organização deste estudo são: escritores consagrados; novas vozes literárias; novos ilustradores de referência; autores traduzidos; editoras especializadas e ações de legitimação e canonização da LIJ portuguesa. Para cada uma das categorias foram selecionadas seis entradas, num total de 36 referências de relevo que, por si só, ajudam na caracterização da edição portuguesa para a infância e a juventude em diferentes domínios e sob perspetivas também distintas, embora complementares. 


\section{a) Autores consagrados}

Decano da literatura portuguesa para a infância, António Torrado (Lisboa, 1939) é autor de uma vastíssima obra dedicada aos leitores mais pequenos, ainda que a sua produção literária não se esgote nesse campo. Reconhecido dramaturgo, autor com residências nas mais importantes e prestigiadas companhias de teatro portuguesas, a sua obra infantil distingue-se pela valorização da herança tradicional e pela sua reescrita, ainda que tenha publicado em praticamente todos os géneros. Além disso, distingue-se pela aposta num universo literário marginalizado, como é o do teatro para crianças e jovens, sendo um dos autores que mais textos publicou neste segmento. A poesia, o conto breve e muito breve, quase sempre caracterizado por um cuidado apurado com a linguagem, que explora de forma exímia, são outras áreas de relevo na produção de uma autor que já publicou seguramente perto de uma centena de livros infantis ao longo de mais de 40 anos de atividade literária praticamente ininterrupta. Juntem-se, ainda, as reflexões de cariz pedagógico sobre a educação e a promoção da leitura, as formações e intervenções públicas que realizou em defesa da sua legitimação e da sua qualidade.

Da mesma geração, Luísa Ducla Soares (Lisboa, 1939) destaca-se pelo papel ativo e profundamente empenhado que sempre adotou em defesa da literatura para a infância de qualidade. A autora que, em 1972, ainda sob o regime ditatorial português, recusou um prémio literário por motivos políticos, tem uma vastíssima obra para os leitores mais pequenos que inclui todos os géneros e percorre uma enorme diversidade de temáticas. Merecem especial destaque os seus livros de poesia — pela qualidade das propostas, desafiadoras em termos de conteúdo e forma- onde é visível uma apurada atenção à palavra. Isso não inibe a presença de uma forte dimensão lúdica, capaz de explorar todas as vertentes da língua: sonora/fónica, morfológica, sintática, semântica, mas também simbólica. Finalmente, uma palavra para os seus contos, onde se revela atenta aos temas atuais (ambiente e ecologia, racismo, imigração...), mas também percursora na inclusão de universos ligados ao fantástico, à ficção científica, sem esquecer a reescrita, mais ou menos subversiva da tradição oral.

Com obra produzida em diferentes géneros, é no romance juvenil que Alice Vieira (Lisboa, 1943) se destaca, tendo mesmo os seus livros provocado uma mudança significativa nessa área a partir do final da década de 70 do século XX. Esta autora portuguesa, finalista do Prémio Andersen, tem publicado romances juvenis onde é possível, através das narradoras protagonistas adolescentes, acompanhar a evolução da sociedade portuguesa das últimas décadas. Temas como o crescimento e a identidade, a família e os afetos, incluindo a sua desestruturação e o impacto dessa crise no universo dos adolescentes, a velhice, mas também a História e a identidade nacional são alvo de uma recriação literária onde está sempre ausente a moralização. Narradora exímia, dotada de uma poderosa e fluída voz narrativa, a escritora consegue, sem recurso a facilitismos e a modas, estabelecer um diálogo próximo com os seus leitores há mais de duas gerações. 
Relevante poeta e cantautor, com atividade política e associativa de diversa índole, incluindo a presidência da Sociedade Portuguesa de Autores, José Jorge Letria (Cascais, 1951) sempre dedicou atenção à literatura infantil, sobretudo à poesia, onde deixa marcas relevantes, sobretudo ao nível da inventividade linguística, mas também pela incursão em géneros não tradicionais, como as greguerías que lhe inspiraram um dos seus melhores livros - Letras \& Letriasrealizado em parceria com o filho, reconhecido ilustrador (e agora também editor), André Letria.

Autor de referência no panorama literário português para a infância e a para a juventude, Álvaro Magalhães (Porto, 1951) distingue-se pelo facto de tratar, de forma recorrente e sistemática, um conjunto de topoi literários cuja universalidade é assinalável e a sua obra configura um caso especial de unidade temática. As relações entre a vida e a morte, surgindo ambas como faces contíguas da existência humana, o tempo, a infância, o amor e a busca de uma existência plena são algumas das referências transversais à poesia, teatro, conto, novela $\mathrm{e}$ romance que tem publicado nas últimas décadas.

António Mota (Baião, 1957) é um dos mais destacados e reconhecidos escritores portugueses de literatura para crianças e jovens. Com uma vasta obra, iniciada em 1979, tem recriado sobretudo o universo rural duriense, que serve de pano de fundo a muitos dos seus textos, especialmente aos romances juvenis. Mais do que cenário ou pano de fundo das intrigas, o Douro, desde a década de 30 do século XX, revela-se uma espécie de topos literário de grande significado, tendo implicações diretas nas vidas e nas personalidades das personagens. A peculiar geografia e o clima daquela região, as duras condições de vida e a atividade rural como principal fonte de rendimento, o isolamento físico e cultural, a organização social muito hierarquizada e impermeável à mudança, dominada pelos homens, as tradições e os rituais, são alguns dos motivos assiduamente recriados, quase sempre perspetivados a partir do ponto de vista de personagens masculinas adolescentes ou no final da infância.

\section{b) Novos autores}

Jornalista freelancer, Carla Maia de Almeida (Matosinhos, 1969) tem-se afirmado, nos últimos anos, como uma autora em crescimento e em amadurecimento contínuo, com publicações para a infância e juventude com cada vez mais qualidade e autenticidade, sobretudo no que diz respeito à descoberta de uma voz pessoal e de um registo original. Irmão Lobo (2013), o seu mais recente trabalho, insere-se no domínio da crossover fiction ao criar um universo narrativo com claras afinidades com a realidade portuguesa contemporânea, marcada pela crise económica e social. As repercussões privadas, em particular na família, dessa crise são o ponto de partida para um romance onde a identidade, o crescimento, os conflitos e as perdas ocupam o centro da atenção. O registo narrativo, dividido em dois momentos diferentes da vida da protagonista, é marcante e facilita a identificação dos leitores e, sobretudo, o seu questionamento e reflexão. 
Conhecido como ilustrador, músico, com trabalho também no domínio do cinema de animação, Afonso Cruz (Figueira da Foz, 1971) venceu o prémio Maria Rosa Colaço em 2009 com o romance juvenil Os livros que devoraram o теи раi, uma metaficção original sobre o universo dos livros e da literatura de cariz quase borgesiano. A sua obra, reconhecida no domínio da ficção para adultos, tem sido alvo de distinções e prémios e caracteriza-se pelo original trabalho literário e linguístico, desafiando a interpretação do leitor e movendo-se nos caminhos da reinvenção genológica e do apagamento das fronteiras entre o real e a ficção. As suas obras também destinadas a crianças mantêm as mesmas características, explorando o limites dos géneros e da linguagem.

A carreira literária de Rita Taborda Duarte (Lisboa, 1973) inicia-se com a publicação de A Verdadeira História de Alice (Caminho, 2004), obra galardoada com o Prémio Literário Branquinho da Fonseca / Expresso / Gulbenkian em 2003, à qual se seguem outras publicações, a maioria delas em parceria com o ilustrador Luís Henriques. Pela originalidade dos temas e, sobretudo, da perspetiva com que são abordados, subversiva e assumidamente lúdica, Rita Taborda Duarte vem desenvolvendo um trabalho literário em constante crescimento e afirmação. Junta-lhe, ainda, uma grande plasticidade discursiva que lhe permite o recurso a múltiplos registos, além de infinitas possibilidades de reinvenção linguística, com consequềncias na promoção de surpreendentes efeitos cómicos. A parceria com Luís Henriques é sintomática do caminho conjunto que ambos têm trilhado, onde se cruzam experimentação, inovação e trabalho com muito divertimento. $\mathrm{O}$ gosto de ambos pela narração de histórias, de boas histórias, simultaneamente engraçadas e questionadoras, tem dado origem a livros capazes de despertarem a atenção de diferentes tipos de leitores, enriquecendo e diversificando o atual panorama literário português para a infância.

Um dos elementos fundadores da Editora Planeta Tangerina, de que falaremos mais adiante, Isabel Minhós Martins (Lisboa, 1974) é responsável pela grande maioria dos textos dos álbuns e narrativas ilustradas da sua casa editorial. A seu discurso, muito simples e acessível, consegue captar a nostalgia da infância, apelando a leitores de diferentes idades e competências leitoras. Nos últimos anos, tem vindo a explorar novos caminhos, assumindo-se como escritora de pleno direito e não como «simples» autora do complemento textual de álbuns. A originalidade das perspetivas narrativas, quase sempre em linha com o ponto de vista infantil, é a sua imagem de marca.

Vencedor do prémio Branquinho da Fonseca/Expresso/Gulbenkian, destinado a autores com menos de 30 anos de idade, David Machado (Lisboa, 1978) iniciou a sua atividade literária na literatura infantil, tendo entretanto publicado vários romances para adultos. A sua obra distingue-se pela presença do humor, resultante do trabalho original com vários tipos de cómico e por uma especial atenção ao universo onírico e à sua erupção no quotidiano das crianças. Divertidos e promotores da imaginação, os contos infantis de David Machado têm conhecido enorme sucesso junto do público infantil.

A mais jovem autora selecionada, também vencedora do Prémio Branquinho da Fonseca/Expresso/Gulbenkian, com o livro $O$ caderno vermelho da rapariga karateca, Ana Pessoa (Lisboa, 1982) publicou em 2014 um segundo 
romance juvenil que confirma as suas qualidades de narradora. Claramente uma das novas vozes da literatura juvenil portuguesa, com apenas dois romances publicados na coleção «Dois Passos e Um Salto», que marca a aposta da Editora Planeta Tangerina no segmento juvenil. Supergigante é a sua segunda obra. Protagonizada e narrada por Edgar, acompanhamos a sua corrida pela cidade e pelas memórias num dia marcado pela morte do avô e pelo seu primeiro beijo.

\section{c) Novos ilustradores}

Ilustradora, designer e editora da Tcharan, Marta Madureira (Porto, 1971) distingue-se pelo trabalho com o recorte e fusão de diferentes texturas, formas, padrões, quase todo realizado digitalmente. Outro aspeto que distingue esta criadora prende-se com a conceção do livro como objeto de design, alvo de uma atenção especial em todas as suas dimensões. Assim, capa, contracapa, guardas, ficha técnica e folha de rosto estabelecem afinidades visuais entre si, seja ao nível dos motivos ilustrados, das cores ou do próprio grafismo.

Yara Kono (São Paulo - Brasil, 1972), já galardoada com o Prémio Nacional de Ilustração, é uma ilustradora de origem brasileira, a viver há vários anos em Portugal, sendo igualmente um dos rostos da editora Planeta Tangerina. A sua ilustração explora o jogo com volumes, formas e texturas, submetendo os textos a uma recriação muito pessoal, onde não está ausente o humor e o comentário irónico. Muito divertidas e apelativas, às vezes caracterizadas por uma ingenuidade que sugere a perspetiva infantil, ao nível dos formatos, por exemplo, as ilustrações fundem-se com o texto, explorando também as potencialidades da mancha gráfica.

Camaleónico, senhor de um traço expressivo e espontâneo, Bernardo Carvalho (Lisboa, 1973) é possivelmente um dos mais talentosos e criativos ilustradores portugueses da nova geração. Explora diversas técnicas e registos e consegue resultados perfeitos ao nível da linguagem visual mais adaptada a cada texto. É, além do mais, ousado e inovador nas propostas, arriscando novas aproximações aos textos que ilustra. Responsável por parte significativa da ilustração e do design da editora Planeta Tangerina, Bernardo Carvalho também é autor de um conjunto interessante de álbuns sem texto, reveladores da sua capacidade de contar histórias através das imagens.

Depois de percorrer vários caminhos, é no jogo com as formas, muitas vezes geométricas, que Madalena Matoso (Lisboa, 1974) se sente em casa. As cores fortes e contrastivas, o desafio dos carimbos ou das texturas e padrões recortados e recombinados acrescentam expressividade e ludicidade aos textos. A criadora é, juntamente com Bernardo Carvalho, responsável por grande parte das obras publicadas pela editora que ajudou a fundar, a Planeta Tangerina, tendo contudo ilustrado vários outros autores em outras casas editoras.

Com residência em Nova Iorque, André da Loba (Aveiro, 1979) tem ilustrado na imprensa internacional com sucesso e sido distinguido com vários prémios. A sua ilustração é claramente distintiva, fruto de uma formação e labor na área de design. Experimental, apostada em explorar o jogo com as formas e 
também com as cores, desenvolve-se em torno de ideias-chave que singularizam o processo criativo do autor. Com imenso potencial de crescimento e de exploração, a obra de André da Loba parece desenvolver-se e metamorfosear-se à medida que o ilustrador vai ganhando experiência e alargando as suas referências.

Vencedora do prémio de ilustração da Feira do Livro Infantil de Bolonha 2014, Catarina Sobral (Coimbra, 1985) é, além de ilustradora, autora de álbuns e uma contadora de histórias através das imagens e das palavras. Tem-se afirmado como uma das mais talentosas ilustradoras da sua geração, com um enorme potencial de crescimento. As suas ilustrações, muito trabalhadas e pensadas, resultam de um processo de criação onde são visíveis referências intertextuais muito eruditas e relevantes, abrindo o leque de leitores e leituras possíveis.

\section{d) Editoras especializadas}

Para além das editoras selecionadas e aqui brevemente caracterizadas, existem outras 2 , como a Tcharan, a Bags of Books, a Gato na Lua ou a Gatafunho, que também se dedicam a este segmento editorial. A nossa escolha recaiu sobre seis delas, com base na análise do respetivo catálogo, tendo em conta as suas especificidades e também uma assinalável identidade. De média ou mesmo muito reduzida dimensão, atuando num nicho de mercado, com maiores ou menores dificuldades, têm conseguido sobreviver exatamente por causa dessa identidade, em alguns casos, já alvo de reconhecimento nacional e internacional, como aconteceu com a Planeta Tangerina ou com a Kalandraka, as duas casas de mais prestígio e dimensão. Refira-se que o aparecimento de várias destas editoras, criadas por escritores ou ilustradores, parece constituir uma resposta à dificuldade de publicação na editoras tradicionais, nomeadamente nas detidas pelos grandes grupos económicos. Assim, não está de todo ausente uma estratégia de autoedição, de que são exemplo a Planeta Tangerina, a Trinta por uma Linha, a Tcharan, ou a Pato Lógico.

Inicialmente criada como ateliê de design, a Planeta Tangerina foi fundada em 1999 por quatro amigos da área do design de comunicação. Em 2006, lançaram-se na aventura da publicação de livros infantis e, a partir daí, nunca mais pararam. As suas publicações, a maioria álbuns, com e sem texto, caracterizam-se pela articulação entre texto e imagens, destinando-se tanto a crianças como a adultos que apreciam livros-objeto bem cuidados. Para além de se terem imposto no mercado português como editora de referência no segmento infantil, têm conseguido vender os direitos de edição das suas obras, alvo de distintos e relevantes prémios nacionais e internacionais, para países como Espanha, França, Itália, Brasil, Reino Unido, mas também a Coreia do Sul ou o Japão. Em 2013, receberam, na Feira do Livro de Bolonha, o Prémio BOP para a mel-

2 Outros projetos editoriais, de menor duração ou mais pontuais, às vezes ligados quase exclusivamente à autoedição, também surgiram no período em apreço. Destaque-se o caso das edições Eterogémeas, de O Bichinho de Conto ou Lobo Bom. 
hor editora europeia, o que ainda veio alargar mais a já vasta rede de contactos da editora que ainda mantém o núcleo duro que a formou, assim como o processo de criação de livro em conjunto, o que explicará o seu sucesso junto dos leitores de diferentes idades, mas também junto da crítica especializada e da própria academia. Constituindo um caso de estudo em várias áreas, nomeadamente em termos da edição, do design e da ilustração, a Planeta Tangerina tem vindo a diversificar a sua oferta editorial, alargando o leque de autores e ilustradores, mas também de géneros, sem abdicar de uma componente experimental, nomeadamente em termos de novos formatos (álbum sem texto, narrativas paralelas, mix-and-match books, não ficção, livro-jogo, livro interativo, etc.) que a caracterizou desde a sua génese.

A Kalandraka é uma chancela galega que, entretanto, se fixou em Portugal. Desde 2002 é responsável pela publicação de obras clássicas da literatura infantil, em particular do álbum, segmento onde se especializou desde a sua criação. As suas várias coleções distinguem-se pelo cuidado muito especial com a ilustração e com a sua ligação ao texto. Integra no seu catálogo muitos autores e livros premiados de distintas origens. Destaque-se a adaptação ao formato álbum de inúmeros textos da tradição oral europeia, alvo de recriação por parte de escritores e ilustradores de referência. Ao mesmo tempo que edita criadores consagrados, também tem procurado descobrir novos talentos, como a instituição do Prémio Kalandraka para álbuns é indicador significativo. No caso da Kalandraka Portugal, é impressionante, para além do número de títulos publicados, a qualidade dos mesmos, constituindo um catálogo de referência obrigatória nas escolas, bibliotecas e até em estudos académicos sobre este segmento.

Criada em 2008, a Trinta por uma linha (Porto, 2008) tem a particularidade de só incluir autores portugueses no seu catálogo, sendo responsável por várias estreias literárias. Dirigida pelo poeta e professor João Manuel Ribeiro, também dá especial atenção à poesia para a infância, género pouco presente na maior parte dos catálogos das grandes editoras, contemplando diferentes tipologias textuais para distintos leitores, nas quais se incluem também recriações da literatura tradicional. Mais recentemente, procurou diversificar o seu catálogo com publicações dirigidas ao universo juvenil. A proximidade da editora em relação aos autores permite a sua divulgação em muitas atividades de proximidade com os leitores, desde lançamentos de livros, a formações e encontros destinados a professores e mediadores, divulgando e promovendo os seus livros em escolas e bibliotecas.

Por seu turno, a Bruaá (Figueira da Foz, 2008) tem apostado num catálogo dominado pela tradução de obras estrangeiras, mais ou menos recentes, onde se incluem alguns clássicos, apenas com uma ou outra exceção. Com um volume de edição muito controlado, dada também a sua dimensão, tem conseguido colocar os seus livros em livrarias especializadas. Muito recentemente, abriu um espaço próprio de comercialização, como outras editoras ${ }^{3}$ também possuem, o que permite o contacto direto com os leitores.

\footnotetext{
3 Veja-se o caso da livraria Gigões \& Anantes, propriedade do editor da Bags of Books, ou da Papa-Livros, que pertence às editoras da Tcharan, ou ainda da Gatafunho, da Orfeu Negro e da
} 
Também criada em 2008, a Orfeu Mini é uma chancela da Orfeu Negro (Lisboa, 2008), editora que se distingue pela promoção da vertente artística dos livros, seja do ponto de vista dos temas, seja dos objetos que publica, alvo de uma atenção muito especial ao nível do design gráfico. Esta característica estende-se igualmente à sua coleção de livros infantis, que tem vindo a crescer a bom ritmo, mantendo grande qualidade. Inicialmente, apostou sobretudo nas traduções, quer de obras clássicas, como $O$ Livro Inclinado, de Peter Newell, a que se vieram juntar as obras de Oliver Jeffers, por exemplo. Mais tarde, apostou, com sucesso, no álbum de autoria única, tendo sido responsável pela estreia de Catarina Sobral. Esta opção já lhe rendeu dividendos, através da visibilidade internacional que a criadora portuguesa tem conhecido.

Finalmente, destaque-se a editora criada por André Letria, conhecido ilustrador português. A Pato Lógico (Lisboa, 2010) caracteriza-se, por um lado, pela diversidade do seu catálogo, onde estão presentes livros que fogem aos modelos mais convencionais (livros de atividades, livro-jogo), mas também pela edição em formato digital, convertendo algumas publicações em aplicações multimédia. A editora inclui ainda um serviço educativo que organiza diferentes atividades relacionadas com os livros e a sua animação e promoção.

\section{e) Traduções de referência de criadores clássicos e contemporâneos}

Ao nível da tradução, os últimos anos também têm sido pródigos em disponibilizar, aos leitores portugueses, algumas obras clássicas emblemáticas, nomeadamente de trabalhos pioneiros no domínio do álbum, mas também de edições contemporâneas, permitindo acompanhar quase em tempo real a edição internacional. Depois de anos de significativo atraso ${ }^{4}$, a verdade é que autores clássicos, com Maurice Sendak, Tomi Ungerer, Shel Silverstein ou mesmo Adela Turín, têm sido alvo de projetos alargados de tradução e edição, em consonância com o seu lugar marcante na evolução da LIJ contemporânea e com a atualidade e continuidade de leituras renovadas que permitem. Destaque-se, ao nível da tradução destes autores, o trabalho de casas editoras como a Bruaá e a Kalandraka, por exemplo. Esta última tem sido responsável também pelas traduções de Eric Carle ou de Anthony Browne, construindo um catálogo onde é possível encontrar algumas das obras mais relevantes dos últimos 50 anos. No que diz respeito ao acompanhamento da edição contemporânea, merecem destaque, para além das editoras já referidas, a Orfeu Mini, responsável pela edição dos livros de Oliver Jeffers ou mais recentemente de David Weisner, por exemplo. A criadora Emily Gravett, reconhecida pelos seus álbuns questionadores e desafiadores dos limites do próprio género, é outra das apostas bem sucedidas, desta vez da editora Livros Horizonte.

\footnotetext{
Bruaá, que têm também espaço próprio de comercialização. Estes espaços livreiros são igualmente locais muito apetecíveis para a realização de atividades como horas do conto, lançamento de livros, encontro com escritores e ilustradores, exposições de originais, entre outras.

${ }^{4}$ Relembre-se, por exemplo, que o álbum Onde vivem os monstros, de Maurice Sendak, cuja primeira edição data de 1963, só foi editado em Portugal em 2009.
} 


\section{f) Ações de legitimação da LIJ portuguesa}

Mas foi na área da investigação que a evolução da LIJ portuguesa foi mais visível, com um aumento considerável de publicações científicas, tanto em publicações periódicas como em volumes monográficos, em Portugal e no estrangeiro, a somar à abertura de cursos, pós-graduações e especializações, que contemplam formação específica na área e dos quais resultaram vários trabalhos académicos (teses de Mestrado e Doutoramento). A realização de eventos de promoção e divulgação da LIJ, bem como seu estudo profundo, com a publicação de atas, a par da publicação de recensões e de textos críticos, em revistas da especialidade, como a Malasartes (entretanto suspensa), ou em secções dedicadas à LIJ, como a Ler ou a Blimunda, mantêm alguma visibilidade sobre o universo da edição infantil. Junte-se o impacto dos prémios literários ou de ilustração (Sociedade Portuguesa de Autores, Branquinho da Fonseca / Expresso / Gulbenkian, Bissaya Barreto, Maria Rosa Colaço ou o Prémio Nacional de Ilustração). Finalmente, destaque-se o impacto do Plano Nacional da Leitura (em vigor desde 2007), de projetos como a Casa da Leitura, ou a implementação das Metas Curriculares do Ensino do Português, onde a literatura para a infância surge desde o $1 .^{\circ}$ ciclo do Ensino Básico.

\section{CONCLUSÕES: DIFICULDADES E DESAFIOS}

Como pudemos constatar, nos últimos anos, assistimos à gradual consolidação da literatura para a infância e juventude, resultante da conjugação de uma série de fatores económicos, sociais, políticos, educativos e também literários e editoriais. A atenção crescente que a LIJ portuguesa, e em particular a ilustração, tem conhecido, mesmo no contexto internacional, não pode, contudo, apagar as dificuldades de vária ordem existentes, nomeadamente em termos da sua divulgação internacional. Assim, constata-se que os autores portugueses não são promovidos de forma consistente e efetiva pelas autoridades portuguesas nem pelas próprias editoras (sobretudo pelos grandes grupos editoriais) que continuam a frequentar as feiras internacionais mais com o objetivo da compra de direitos do que da sua venda. Por seu turno, os ilustradores portugueses têm conseguido, praticamente à custa do seu trabalho e esforço, alguma visibilidade e reconhecimento internacionais que não se estendem aos textos e aos escritores, trabalhando para casas editoriais internacionais ou fazendo as suas carreiras maioritariamente fora do país, como acontece com André da Loba.

A investigação, apesar de ter aumentado consideravelmente nos últimos anos, ainda é marginal, pontual e muito localizada em duas ou três figuras de referência. A sua internacionalização praticamente não existe e são pontuais os artigos publicados em revistas de referência internacionais. Estas, por sua vez, são pouco recetivas à publicação de trabalhos sobre autores e obras não traduzidos para outras línguas e não disponíveis para a audiência internacional a que estes periódicos se destinam. A ausência de publicações científicas sobre a LIJ em Portugal, depois da suspensão da edição da Revista Malasartes em nada facilita a divulgação da investigação realizada no país. 
A edição de literatura para a infância e juventude em Portugal, centrada em dois grandes grupos económicos, coloca as pequenas editoras em grandes dificuldades que têm sabido contornar com muito trabalho, imaginação e aposta na qualidade. Contudo, a crise económica tem colocado inúmeros obstáculos à sua sobrevivência que é cada vez mais difícil.

Ainda assim, verifica-se um aumento da quantidade em termos da oferta, o que tem como consequência o abafamento da visibilidade da qualidade de algumas obras. A falta de visibilidade mediática (em termos de divulgação e promoção) da LIJ de qualidade é outro dos aspetos a ter em conta, dada a sua ausência nos meios de comunicação como a imprensa generalista, a televisão ou mesmo as revistas de divulgação literária.

\section{REFERÊNCIAS BIBLIOGRÁFICAS}

Gomes, J. A. (1998) Para uma história da Literatura Portuguesa para a Infância, Lisboa, Instituto do Livro e das Bibliotecas.

Lemos, E. (1972) A Literatura Infantil em Portugal, Lisboa, Ministério da Educação Nacional - Direcção Geral da Educação Permanente.

Pires, M. L. B. (1983) História da Literatura Infantil Portuguesa, Lisboa, Vega.

Ramos, A. M. (2012) Tendências contemporâneas da literatura portuguesa para a infância e juventude, Porto, Tropelias \& Companhia.

Rocha, N. (1984) Breve História da Literatura para Crianças em Portugal, Lisboa, ICALP.

- (1992) Breve História da Literatura para Crianças em Portugal, Lisboa, Instituto de Cultura e Língua Portuguesa - Ministério da Educação (2. ${ }^{a}$ ed.).

- (2001) Breve História da Literatura para Crianças em Portugal (nova edição actualizada até ao ano 2000), Lisboa, Caminho.

Roig Rechou, B.-A., Lucas Domínguez, P. e Soto López, I. (coord.) (2007) Teatro Infantil. Do Texto á Representación, Vigo, Edicións Xerais de Galicia.

Roig Rechou, B.-A., Soto López, I. e Neira Rodríguez, M. (coord.) (2009) A Poesía Infantil no Século XXI (2000-2008), Vigo, Edicións Xerais de Galicia.

- (2011) O Álbum na Literatura Infantil e Xuvenil (2000-2010), Vigo, Edicións Xerais de Galicia.

- (2012) A narrativa xuvenil a debate (2000-2011), Vigo, Edicións Xerais de Galicia.

- (2013) Premios Literarios e de Ilustración na LIX. Vigo, Edicións Xerais de Galicia.

Silva, S. R. (2013) Presença e Significado de Manuel António Pina na Literatura Portuguesa para a Infância e a Juventude, Lisboa, Fundação Calouste Gulbenkian/Fundação para a Ciência e a Tecnologia. 